\title{
特集記事
}

\section{マイクロニードルの開発における可視化 〜蚊を模倣した痛みの少ない注射針の開発〜}

\author{
青柳 誠司**

\section{Visualization in Development of Microneedle - Development of Painless Needle Imitating Mosquito -}

\author{
Seiji Aoyagi
}

\section{1. 緒 論}

生体組織検査, 経皮ドラッグデリバリー, 神経電位検 出, 糖尿尿病患者における血液採取・インスリン注射等 の多数の医療行為において，針または針状のツールの低 侵襲化が望まれている，特に，糖尿病患者は血糖值測定 のために, 1 日 2 〜回採血を行わなければいけない. この採血は, 一般的には, 金属製のストレートな形状の 中実な針（ランセット）を，ばねを有する穿刺補助器具 へ取り付け，ばねの復元力を利用して瞬間的に皮膚に突 き刺して微量の出血を生じさせ，これを血糖值を測定す るセンサチップに吸いこませることにより行われている. この採血は痛みを伴い, 患者にとって大きなストレスと なっており，そのストレスから血糖值測定を意り症状を 悪化させる患者も多い.このため低侵襲性のランセット が医療現場で望まれている。痛みの主要な原因として, 現状の金属製の針が概ね直径 $300 \mu \mathrm{m}$ 以上と比較的太く, このため皮膚の痛点 (自由神経終末), を避けることが 困難であることが挙げられる1). 痛点は皮膚上に約 1 $\mathrm{mm}$ 間隔で分布している2).

一方，人間は蚊に刺されてもほとんど痛みを感じない. このため, 蚊の針は低侵襲な針を開発する上で格好の手 本となる. 蚊の穿刺に伴う痛みが少ない理由の一つとし て, 針の直径が約 30〜 $60 \mu \mathrm{m}$ と非常に小さく皮膚の痛点 を避けやすいことが挙げられる 細くすることで無痛針を実現しようという研究が，単結 晶シリコン 5)-7), 金属 ${ }^{8)}$, ポリマー910)を材料として多数 行われてきた5)-10). 製品レベルでも，プレス加工を用い た直径 $180 \mu \mathrm{m}$ の金属製の微細針が近年商品化されてい る11).これらの針において痛みが低減されたことが一部 報告されているものの，単純に針を細くするという手法 だけでは未だ完全な無痛針は実現されておらず，さらな る痛みの軽減の余地があるものと思われる。針を細くす

* 原稿受付 2013 年 7 月 22 日

** 非会員関西大学システム理工学部機械工学科（ 564-8680 大阪府吹田市山手町 3-3-35, E-mail : aoyagi@kansai-u.ac.jp)
ることは，針が座屈しやすくなるという問題も引き起こ す，座屈した針は皮膚に刺さらず，採用する材料によっ ては座屈変形に伴い過大な応力が発生し，折損破壊に至 る恐れもある，単純に針を細くするだけでは，痛みを低 減するという観点からは限界があるものと考える.

筆者は, 針の細さ以外に, 針の形状, 針の刺し方が蚊 の穿刺の痛みの低減に寄与しているのではないかと考え, 蚊の針の詳細な形状観察, 高速度カメラと長作動距離拡 大レンズを用いた蚊の穿刺動作の詳細観察を行ってきた. 本稿ではこれらの結果について紹介するとともに, 観察 結果に基づいて蚊を生体模倣することにより作製したマ イクロニードルおよびそれを用いた人工皮膚への穿刺実 験についても紹介する.

\section{2. 蚊の針と穿刺動作の観察}

筆者の研究室で撮影した蚊の針の光学顕微鏡写真, 電 子顕微鏡 $(\mathrm{SEM})$ 写真, および蚊の針の構造の模式図 をFig. 1 に示す ${ }^{12)}{ }^{13)}$. 蚊の針は，血液の通り道である上 唇 (Labrum), 唾液の通り道である咽頭（Pharynx）, 大顎（Mandible） 2 本，子嚆 (Maxilla) 2 本の合計 6 個の器官が口針を構成し，口針が鞘状の下唇 (Labium) に納まる構造を有する。この図からも観察できるように, 子顎の先端はギザギザ形状をしている．これら各器官が それぞれ有機的に働いて痛みの少ない穿刺が行われてい るものと思われるが, 未だその穿刺メカニズムは正確に 解明されていない.

筆者らは, 皮下に挿入された蚊の針の詳細な動作を解 明するため, 高速度カメラ（ナックイメージテクノロ ジー, MEMRECAM fx-K5, ISO 感度 32,000）と長作 動距離拡大レンズ (ライカ, Z16APO, 最大光学倍率 : 115）を使用して蚊の穿刺動作を撮影した。基本設定は, $1280 \times 1024$ pixels, 1,000flame/s, 光学倍率 50 倍, ワーキングデスタンス : $39 \mathrm{~mm}$ とした。

穿刺対象として生物の皮膚と機械的な特性が同等な透 明な樹脂を利用することにより ${ }^{14)}$ ，人間の不透明な皮下 で蚊の針がどのような動きをしているのかを模擬観察で きるようにした。 


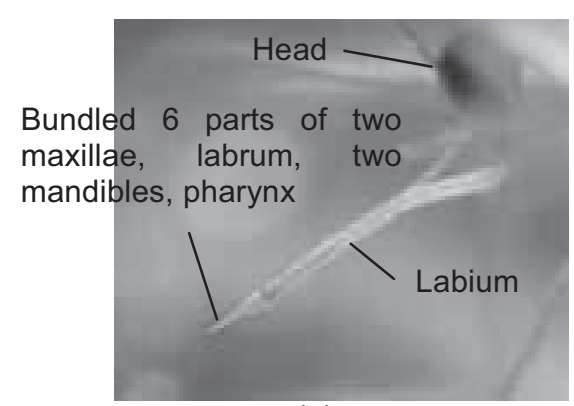

(a)

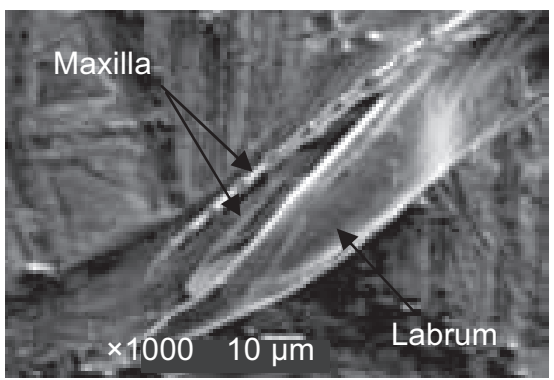

(c)

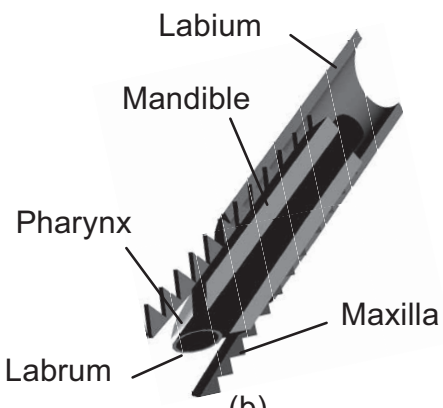

(b)

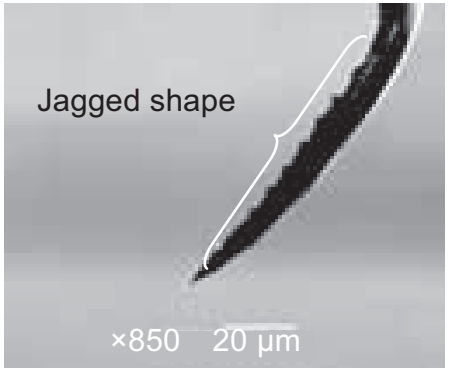

(d)

Fig. 1 Magnified images of mosquito proboscis. (a) optical image of overview. (b) schematic composition of seven parts. (c) SEM image of labrum and maxilla. (d) magnified SEM image of tip of maxilla. Harpoon-like jagged shape is seen.
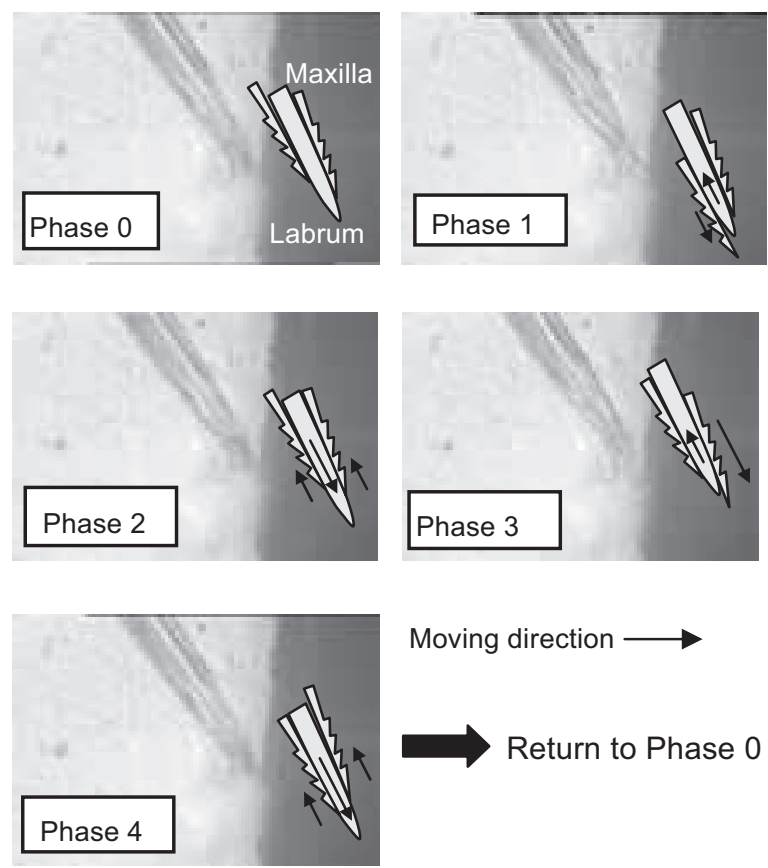

Moving direction $\longrightarrow$

Return to Phase 0

Fig. 2 Mosquito's penetrating motion captured by high-speed camera and magnification lens with long working distance.

その結果，蚊が上唇と一対の小顎を交互に突き出すよ うに協調動作させながら，徐々に皮膚の奥へと針全体を 穿刺していることが確認された。この様子を Fig. 2 に 示す ${ }^{15)}$. 撮影結果を受けて, 蚊の上唇と小顎を交互に突 き出す動作を有限要素法シミュレーションで再現するこ とにより，蚊の穿刺動作のメカニズムを推定した16).そ

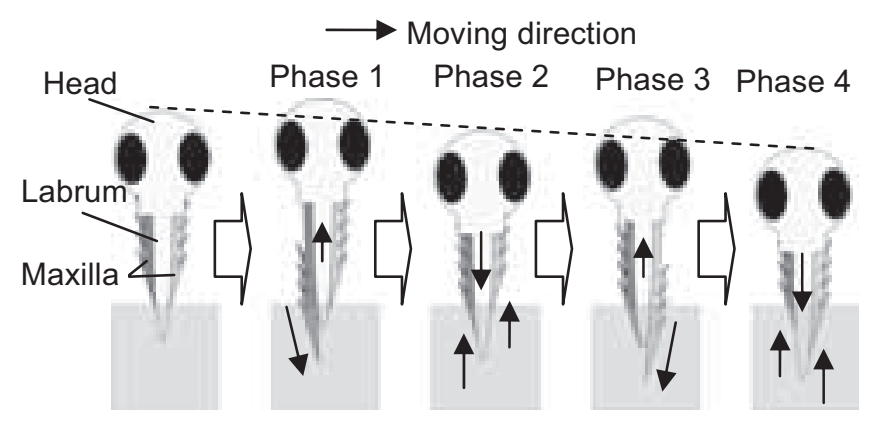

Fig. 3 Schematic motion of mosquito proboscis based on observation. The head and three needles are gradually lowered from Phase 1 to Phase 4 . These phases are repeated at several $\mathrm{Hz}(2 \mathrm{~Hz}$, ranging $1-7 \mathrm{~Hz})$.

の結果，小顎先端に存在する鋸歯状の突起が穿刺の際に 以下のような役割を果たしていると考えられる：(1)鋸の 刃のように皮膚を切り裂く, (2)小顎が前進する場合, 突 起先端付近のみで針が皮虐と接するので, 接触面積が減 少する。これに伴い接触抵抗が低減される, (3)小顎が後 退する場合, 皮䖉に鋸歯状の突起が食い込み, 上唇の前 

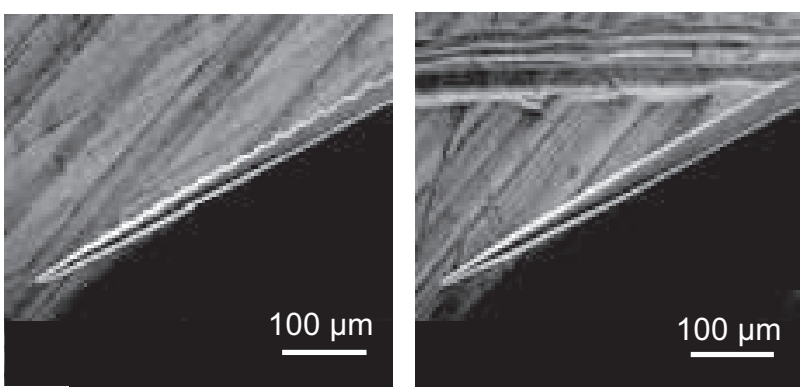

(a)

(b)

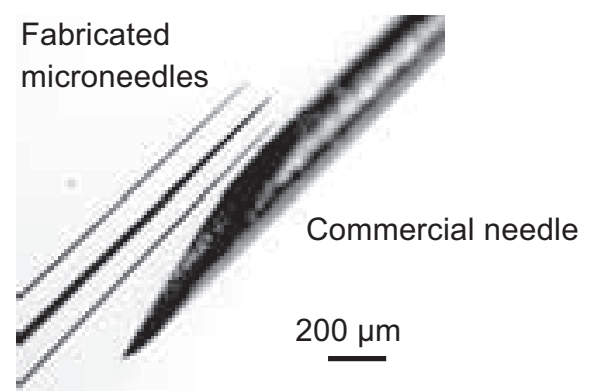

(c)

Fig. 4 Fabricated miconedles. (a) jagged needle imitating maxilla, (b) straight needle imitating labrum. (c) fabricated three needles to be bundled and commercial needle for reference (diameter $0.2 \mathrm{~mm}$ ).

進を補助する足場（アンカー）となる. 高速度カメラに よる観察結果とシミュレーション結果により推定される 蚊の穿刺メカニズムを Fig. 3 に模式的に示す.

\section{3. 蚊を模倣したマイクロニードルの作製}

MEMS (Micro Electro Mechanical Systems)で用いら れる加工技術と, 電解エッチング技術とを併用すること により，Si 製のマイクロニードルを作製した ${ }^{15)}$. Fig. 4 に作製したニードルの顕微鏡写真を, Fig. 5 にその模式 図を示す。この針は 3 本 1 組となっており, 両端の 2 本 の針には蚊の子顎を模して鋸歯状の突起が付与されてい る.

3 本の針を蚊の穿刺動作を模して協調動作させながら ゴム製の人工皮膚に穿刺し，その際の穿刺抵抗力を測定 した ${ }^{15)}$. 結果を Fig. 6 に示す. 3 本の針を協調させずに 一体化して振動を加えずに穿刺する（Mode A), 同じ く 3 本の針を一体化して振動を加えて穿刺する（Mode B), 3 本の針を独立させ, 時間的位相差を設けて交互 に前進，後退させながら穿刺する（Mode C）の刺し方 のうち，蚊の動作を模倣した Mode Cが一番小さい抵抗 力で穿刺が可能であることが判明した.

穿刺抵抗力と痛みは比例関係になく，また痛みには個 人差があるものの, 両者には正の相関があることは明ら かである．被験者を用いて治験を行うことで, 針径を微 細にすること, および, 針を複数本 ( 3 本) に分割して 協調して動かすことで, 痛みがどの程度減少するかの評 価を行うことを検討中である.

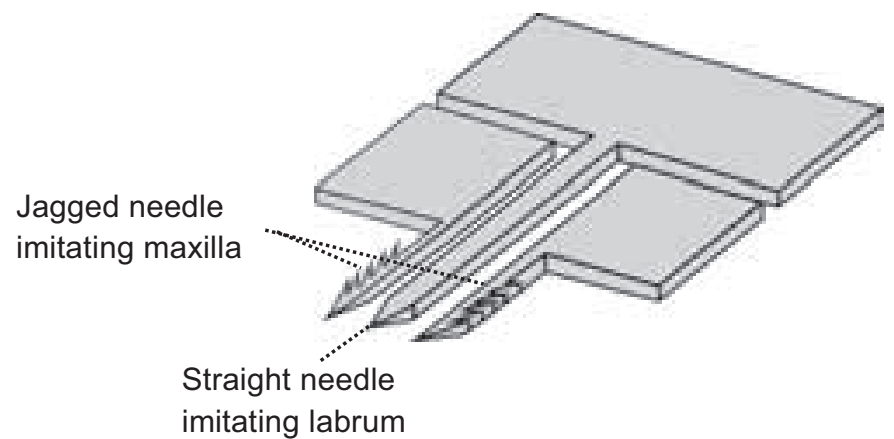

Fig. 5 Schematic of three bundled microneedles

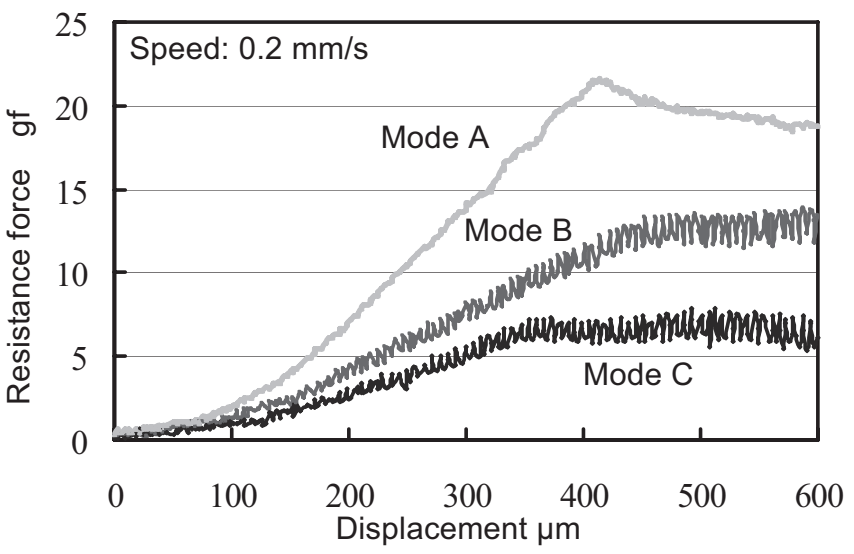

Mode A Move forward without vibration

Mode B

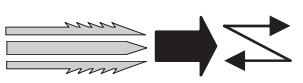

Move forward

with simple vibration

Mode C

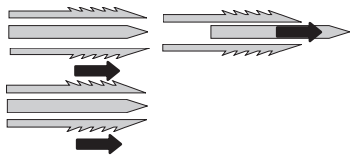

Move forward

with cooperative vibration

Fig. 6 Transition of resistance force during inserting the three needles to silicone rubber. In mode B and C, vibration frequency was set to $30 \mathrm{~Hz}$. The vibration amplitude was set to $140 \mu \mathrm{m}$.

\section{4. 結 言}

無痛針の手本として蚊の針に着目し，高速度カメラと 長作動距離拡大レンズを組み合わせたシステムを用い, 蚊の穿刺動作の詳細観察を行った. その結果, 針が複数 本の針が束ねられてできており，そのうちの 2 本（小 顎）の先端部分に独特のギザギザ形状の突起があること, 穿刺時に血液を吸引する主要な針である上唇とその左右 の小顎の合計 3 本が，互いに時間的位相差を持って協調 動作をしながら穿刺が行われていることを解明した.

上唇と, 小顎 2 本の合計 3 本の針について, それらと 同様の形状・法を持つ 3 本の針をマイクロマシニング の技術を用いて工学的に実現した。これらの針を蚊と同 
様に互いに位相差を持たせて協調動作させ，人工皮膚へ の穿刺実験を行った結果，穿刺抵抗力が $1 / 3 \sim 1 / 4$ に 低減されることが確認できた。

現在, 血液の吸引, 薬液の吐出が行えるように, 穴を 有する中空マイクロニードルの開発に取り組んでいる ${ }^{17)}$. また蚊の下唇の動作に注目し，針をサポートして座屈を 防止する治具の開発も行っている ${ }^{18)}$.

\section{謝 辞}

本研究は独立行政法人日本学術振興会の科研費 （23656188）の助成を得た。本研究は，平成 25 年度関西 大学研究拠点形成支援経費において, 研究課題「蚊を模 倣した中空針のマイクロ加工と低侵襲歯科医療への応 用」として研究費を受けた。また，平成 25 年度関西大 学先端科学技術推進機構の研究グループ助成において, 研究課題「生体適合材料のナノ・マイクロ加工と医療へ の応用」として研究費を受けた.

\section{参考文献}

1) 青柳誠司，泉 隼人: MEMS 技術を援用したマイクロニードル の開発, 精密工学会誌, Vol.74, No.11 (2008) pp.1156-1159.

2 ) 前野隆司：ヒト指腹部と触覚受容器の構造と機能, 日本口 ボット学会誌, Vol.18, No.6 (2000) pp. 772-775.

3 ) 池庄司敏明 : 蚊, 東京大学出版会 (1993) pp.189-214.

4 ) Oka, K., Aoyagi, S., Arai, Y., Isono, Y., Hashiguchi, G., Fujita, H.: Fabrication of a Micro Needle for a Trace Blood Test, Sensors and Actuators, Vol. 97-98C (2002) pp. 478-485.

5 ) Henry, S., MecAllister, D. V., Allen, M. G., Prausnitz, M. R.: Micromachined Needles for the Transdermal Delivery of Drugs, Proceedings of IEEE International Conference on Micro-electro-mechanical Systesms (MEMS '98) (1998) pp. 494-498.

6 ) Campbell, P. K., Jones, K. E., Huber, R. J., Horch, K. W., Normann, R. A.: A Silicon-Based, Three-Dimensional Neural Interface: Manufacturing Processes for an Intracortical Electrode Array, IEEE Transaction Biomedical Engineering, Vol. 38, No. 8 (1991) pp.758-768.

7 ) Najafi, K., Ji, J., Wise, K. D.: Scaling Limitations of Silicon
Multichannel Recording Probes, Journal of Biomedical Engineering, Vol. 37, No.1 (1990) pp. 1-11.

8 ) Chandrasekaran, S., Brazzle, J. D., Frazier, A. B.: Surface Micromachined Metallic Microneedles, Journal of MEMS, Vol. 12, No. 3 (2003) pp. 281-288.

9 ) Moon, S. J., Lee, S. S.: Fabrication of Microneedle Array Using Inclined LIGA Process, Technical Digest Transducers '03 (2003) pp. 1546-1549.

10) Stupar, P. A., Pisano, A. P.: Silicon, Parylene, and Silicon/Parylene Micro-Needles for Strength and Toughness, Technical Digest Transducers ’01 (2001) pp. 1386-1389.

11) http://www.terumo.co.jp/

12) Aoyagi, S., Izumi, H., Aoki, T., Fukuda, M.: Development of a Micro Lancet Needle Made of Biodegradable Polymer for Low Invasive Medical Treatment, Technical Digest Transducers'05 (2005) pp. 1195-1198.

13) Aoyagi, S., Izumi, H., Fukuda, M.: Biodegradable Polymer Needle with Various Tip Angles and Effect of Vibration and Surface Tension on Easy insertion, Sensors and Actuators, Vol. A143 (2008) pp. 20-28.

14）高柳弘輝, 田中隆寛, 中尾 健, 鈴木昌人, 高橋智一, 青柳誠 司：アルギン酸ゲルを用いた模擬皮膚組織の開発およびこれ を用いた蚊の穿刺動作の観察, 日本機械学会第 4 回マイク ロ・ナノ工学シンポジゥム講演論文集 (2012) CDROM $\mathrm{P}-\mathrm{OS} 3-6$.

15) Izumi, H., Suzuki, M., Aoyagi, S., Kanzaki, T.: Realistic imitation of mosquito's proboscis: electrochemically etched sharp and jagged needles and their cooperative inserting motion, Sensors and Actuators. Vol. A 165-1 (2011) pp. 115-123.

16) Aoyagi, S., Takaoki, Y., Takayanagi, H., Huang, C-H., Tanaka, T., Suzuki, M., Takahashi, T., Kanzaki, T., Matsumoto, T. Equivalent negative stiffness mechanism using three bundled needles inspired by mosquito for achieving easy insertion, 2012 IEEE/RSJ International Conference on Intelligent Robots and Systems (IROS2012) (2012) pp. 2295-2300.

17）田中隆寛, 高柳弘輝, 中尾 健, 高橋智一, 鈴木昌人, 青柳誠 司：タングステン中空マイクロニードルの開発と性能評価, 日本機械学会第 4 回マイクロ・ナノ工学シンポジウム講演論 文集 (2012) CDROM OS3-2-4.

18）寺田善彦, 高橋智一, 鈴木昌人, 青柳誠司：蚊の下唇を模擬 したマイクロニードルの座屈防止用ガイドの設計, ロボティ クス・メカトロニクス講演会 2013 論文集，（2013）CDROM $1 \mathrm{~A} 2-\mathrm{A} 10$. 